\title{
BMJ Open Demographic and social correlates and indicators for behavioural compliance with personal protection among Chinese community-dwellers during COVID-19: a cross-sectional study
}

\author{
Xin Xu, ${ }^{1,2}$ Kimberly Ann Chew (1) , ${ }^{2}$ Xiaolin Xu, ${ }^{1}$ Zhihua Wu, ${ }^{1}$ Xiaohua Xiao, ${ }^{1}$ \\ Qian Yang ${ }^{3}$
}

To cite: Xu X, Chew KA, Xu X, et al. Demographic and social correlates and indicators for behavioural compliance with personal protection among Chinese community-dwellers during COVID-19: a crosssectional study. BMJ Open 2021;11:e041453. doi:10.1136/ bmjopen-2020-041453

- Prepublication history and additional material for this paper is available online. To view these files, please visit the journal online (http://dx.doi.org/10. 1136/bmjopen-2020-041453).

Received 09 June 2020

Revised 26 November 2020

Accepted 09 December 2020

Check for updates

(C) Author(s) (or their employer(s)) 2021. Re-use permitted under CC BY-NC. No commercial re-use. See rights and permissions. Published by BMJ.

For numbered affiliations see end of article.

Correspondence to

Professor Qian Yang; chianyoung@zju.edu.cn

\section{ABSTRACT}

Objectives Examine compliance with personal protective measures in communities for the prevention and control of local transmission of the COVID-19, and explore indicators for such behavioural compliance.

Design Cross-sectional design with a self-selecting sample. Data collected in February 2020.

Setting Community dwellers in China.

Participants 2956 participants aged 16 and above completed the study and were included in the analysis.

Outcome measures Nationwide COVID-19 survey.

Demographics and self-reported compliance with four personal protective measures_-home quarantine, mask-wearing, temperature-taking and hand-sanitising were collected. Outbreak severity and timeliness of personal protection order were obtained from the China Center for Disease Control and Prevention website. Logistic regression models were employed to examine the association between demographic and social indicators and behavioural compliance.

Results Compliance with home quarantine was only associated with gender (men, $\mathrm{OR}=0.61(0.51-0.73)$, inverse association) but no other indicators. In contrast, men had higher compliance with mask-wearing $(\mathrm{OR}=1.79(1.49-2.16))$ and temperature-taking $(\mathrm{OR}=1.27$ (1.05-1.53)). Compared with younger adults ( $\leq 20$ years), the middle-age groups ( $31-40$ and 41-50 years of age) were more compliant with all protective behaviours, except for home quarantine $(\mathrm{OR}=0.71(0.54-0.93)$ and 0.67 (0.46-0.97), respectively).

Conclusion Male gender was associated with lower compliance with home quarantine yet higher compliance with mask-wearing and temperature-taking. The middle-age participants (31-50 years) had lower compliance with home quarantine but higher with other measures. These findings may be supported by the economic considerations and the long-inherited Confucian values among Chinese. In light of the ongoing COVID-19 pandemic, public health authorities should tailor policy implementation to disparities in psychosocial indicators.

\section{INTRODUCTION}

In light of the COVID-19 outbreak that started in December 2019, the Chinese Government has taken a number of strict mitigation
Strengths and limitations of this study

- Extensive data collected during the peak of the COVID-19 outbreak in China ( $\left.\mathrm{n}_{\text {completed }}=2956\right)$.

- Data were collected from multiple provinces with various levels of risk exposure to avoid bias in the sample (categorised using the number of confirmed cases reported by China Center for Disease Control and Prevention).

- The effect of other demographical variables (eg, education, occupational status) was limited due to the lack of data.

- Survey was available online only, hence sample was limited to those with access to digital technology and Internet.

- More mental health-related questionnaires (eg, depression, anxiety) should be collected and analysed as potential indicators for behavioural compliance.

strategies to expedite the tracking, testing and treatment of COVID-19. To prevent and control the transmission of the virus in local communities, the aggressive social distancing order has been enforced nationwide in China as early as from 25 January 2020. Notably, prevention and control measures have been implemented in three phases: (1) suspension of intracity and intercity transportation, and strict control of importation and exportation of COVID-19 cases from Wuhan and other provinces, (2) delaying the severity and rise in cases through several safety measures, (3) decreasing clusters, using standardised protocols and execution of 'scientific evidencebased policy'. Examples of such measures include the closure of wet markets, contact tracing, temperature-taking, health declarations, quarantine, disallowing large gatherings and implementation of strict travel restrictions. ${ }^{12}$ Through strict compliance of 
Chinese citizens to the order, social distancing has been proven the most effective measure to ease the rapid spreading of the virus. ${ }^{34}$

Among all prevention and control measures, a nationwide movement restriction order was announced by the Chinese government soon after the lockdown of Wuhan city on 23 January 2020. This social distancing order was introduced and enforced subsequently, requiring all citizens to remain at home and avoid most forms of face-to-face social contact when outside. The order was implemented with the recommendation of other personal protective measurements, such as regular handsanitising, daily temperature-taking and mask-wearing. ${ }^{5}$ The implementation of the personal protection order was challenging. Social distancing means staying away from mass gatherings and keeping a distance of 6 feet or $2 \mathrm{~m}^{3}{ }^{3}$ Due to the Chinese New Year celebration, which took place around the same time (25 January 2020) when the outbreak happened, movements among cities and suburban areas, as well as family gatherings were inevitable and difficult to contain. Voluntary behavioural intervention during an infectious disease outbreak, such as social distancing, requires not only sufficient realisation of the situation severity, but more importantly, determined commitment to such action from individuals in the community.

Hence prior to the enforcement of the nationwide home quarantine order, the Chinese government announced a series of precautionary regulations, including (1) refusal of entry into public places without wearing a mask and obtaining a normal body temperature; (2) set-up of a detailed individual purchase record of fever/cough/influenza-related medications in local pharmacies; (3) screening and a detailed registry of suspected cases with high fever in the community. The entire enforcement was accompanied by thorough public health education and promotion which started as early as late January. Violation of the abovementioned regulations could result in further investigation or even legal liability. ${ }^{6}$

After the implementation of the four personal protective behaviours, including home quarantine, mask-wearing, temperature-taking and hand-sanitising, non-compliance would lead to strict education and immediate correction from various levels of management, ranging from the street and community, to district and city levels of local authority.

The implementation of these personal protective behaviours is necessary. However, compliance to these actions is not only determined by the severity of the disease, but also a number of demographic (eg, gender, age) and social factors. ${ }^{78}$ Interestingly, while previous literature have demonstrated that older people and women are typically more likely to practice protective behaviours in public health emergencies such as the severe acute respiratory syndrome and $\mathrm{H} 1 \mathrm{~N} 1$ swine flu, the results are mixed. ${ }^{9}{ }^{10}$ Hence in the present study, we sought to understand the demographic indicators and correlates of individuals' compliance to preventive measures during COVID-19.

\section{METHODS}

\section{Study design and sampling}

With a cross-sectional study design, a nationwide online survey on behavioural compliance during COVID-19 was carried out during 14-17 February 2020, among Chinese citizens in China. Community dwellers aged 16 and above were enrolled in the survey. To avoid bias in the sample, the study team disseminated the survey questionnaire nationwide in all 31 provinces and regions in China with different levels of risk exposure. Study description and questionnaires were posted through various social media platforms, such as Wechat and Weibo, with a notice and invitation on these platforms for better visibility. All participants from this self-selecting sample provided electronic informed consent prior to taking the survey (online supplemental material 1). Strengthening the Reporting of Observational Studies in Epidemiology cross-sectional reporting guidelines were used. ${ }^{11}$

\section{Questionnaires}

De-identified demographic information (age, gender, current living area) was collected.

\section{Outbreak severity}

Severity of the outbreak in each province and region in all survey areas was sorted into five categories according to the confirmed COVID-19 cases published on the China Center for Disease Control and Prevention website on the day of the survey (14 February 2020): $<100$ cases, 100-499 cases, 500-999 cases, 1000-1999 cases, $>2000$ cases.

\section{Policy timeliness}

Timeliness of the social distancing order implemented by the provincial government was assessed by the length (in days) between the implementation date of the social distancing order to the date of the survey. For those areas where the order was implemented after the survey, the score '0' was granted, for example, Nei Meng province. Scores were subsequently transformed into fractional rank for analysis purposes.

\section{Compliance to mitigation measures}

An individual's compliance with a number of mitigation measures introduced by the local government was defined as:

1. Home quarantine, as defined by leaving residential address for $\leq 1$ in 3 days' time, as per the Chinese government's regulation.

2. Mask-wearing, as defined by wearing a mask when leaving the residential address on the day of the survey, as per the Chinese government's regulation.

3. Temperature-taking, as defined by taking one's own temperature at least once on the day of the survey, as per the Chinese government's regulation. 
4. Hand-sanitising, as defined by sanitising one's hands with a sanitiser with $>75 \%$ alcohol on the day of the survey, as per the Chinese government's regulation.

\section{Statistical analysis}

Associations among four individual protective behaviours were examined using $\chi^{2}$. Logistic regression models were applied to investigate the indicators for accordance with each individual mitigation measure. All analyses were performed using SPSS V.25 and SAS V.9.4. Statistical significance was determined as two-tailed $p$ value $<0.05$. Bonferroni correction was employed to obtain an adjusted significance level for each protective behaviour: $\approx 0.05 / 4=0.0125$.

\section{Patient and public involvement}

No patients and none of the public were involved in the study planning, design and interpretation of results. Results from the paper will be disseminated to the general public through online article format.

\section{RESULTS}

A total of 3000 participants completed the survey, among whom, 7 had incomplete data and 37 had repeated answers and were removed from the dataset, leaving a total of 2956 in the current analysis. All 2956 subjects completed all questionnaires in the survey. Sample descriptives are in table 1.

\section{Compliance with individual protective measures}

Compliance with home quarantine was positively associated with compliance with hand-sanitising $\left(\chi^{2}=4.21\right.$, $\mathrm{p}=0.023$ ), but not with mask-wearing and temperaturetaking ( $p=0.07$ and 0.08 in the positive direction, respectively). Compliance with mask-wearing was positively associated with temperature-taking $\left(\chi^{2}=493.11, \mathrm{p}<0.001\right)$ and hand-sanitising $\left(\chi^{2}=498.55, \mathrm{p}<0.001\right)$. Compliance with temperature-taking was positively associated with hand-sanitising $\left(\chi^{2}=802.16, p<0.001\right)$.

Logistic regression analysis was employed to investigate the predictors for compliance with each mitigation measure: home quarantine, mask-wearing, temperaturetaking and hand-sanitising. Results showed that higher risk-exposure was positively associated with compliance with all measures except home quarantine. Age was positively associated with higher compliance with maskingwearing and hand-sanitising $(p<0.0125)$, yet inversely associated with home quarantine. Interestingly, while the male gender was associated with lower compliance with home quarantine order, it was found positively associated with mask-wearing and temperature-taking behaviours (table 2).

Gender-specific compliance with each personal protective measure is presented in figure 1 .

While men were less prone to be compliant with home quarantine order, they were more likely to abide by the other three personal protective measures.

\begin{tabular}{|c|c|c|}
\hline & Whole sample & Range \\
\hline \multicolumn{3}{|l|}{ Demographics } \\
\hline Age $($ mean $\pm S D)$ & $28.5 \pm 8.6$ & $16-72$ \\
\hline Gender, female, n (\%) & 1178 (39.9) & \\
\hline \multicolumn{3}{|l|}{ Current living area, $\mathrm{n}(\%)$} \\
\hline $\begin{array}{l}\text { Extremely high risk ( } \geq 2000 \\
\text { confirmed cases) }\end{array}$ & $106(3.5)$ & \\
\hline $\begin{array}{l}\text { High risk ( } 1000-1999 \\
\text { confirmed cases) }\end{array}$ & $667(22.2)$ & \\
\hline $\begin{array}{l}\text { Moderate-high risk (500-599 } \\
\text { confirmed cases) }\end{array}$ & $770(25.7)$ & \\
\hline $\begin{array}{l}\text { Moderate risk (100-499 } \\
\text { confirmed cases) }\end{array}$ & $1290(43.0)$ & \\
\hline $\begin{array}{l}\text { Mild-moderate risk ( }<100 \\
\text { confirmed cases) }\end{array}$ & $167(5.6)$ & \\
\hline $\begin{array}{l}\text { Average length of } \\
\text { implementation of mitigation } \\
\text { measures, days (mean } \pm S D \text { ) }\end{array}$ & $15 \pm 5.1$ & $0-20$ \\
\hline \multicolumn{3}{|l|}{ Compliance to mitigation measures } \\
\hline \multicolumn{3}{|c|}{$\begin{array}{l}\text { Home quarantine, compliant, } 2234 \text { (75.6) } \\
\mathrm{n}(\%)\end{array}$} \\
\hline $\begin{array}{l}\text { Mask-wearing, compliant, } \\
\mathrm{n}(\%)\end{array}$ & $2353(79.6)$ & \\
\hline $\begin{array}{l}\text { Temperature-taking, } \\
\text { compliant, } \mathrm{n}(\%)\end{array}$ & $2350(79.5)$ & \\
\hline $\begin{array}{l}\text { Hand-sanitising, compliant, } \\
\text { n (\%) }\end{array}$ & $2257(76.4)$ & \\
\hline
\end{tabular}

Interestingly, from the distribution graph, the mid-age groups (31-40 and 41-50) was the most non-compliant age group for home quarantine order, nevertheless also the most compliant for other protective behaviours (figure 2).

Further analysis showed that, the 31-40 age group was less compliant to the home quarantine order $(\mathrm{OR}=0.71$ $(0.54-0.93))$, compared with the reference group $(\leq 20$; figure 3). Yet, they were compliant to mask-wearing $(\mathrm{OR}=1.96,95 \% \mathrm{CI}=1.46-2.64)$, hand-sanitising $(\mathrm{OR}=2.24$, 95\% $\mathrm{CI}=1.70-2.96)$ and temperature-taking $(\mathrm{OR}=1.65$, 95\% CI=1.23-2.21). A similar pattern for compliance was also observed in the 41-50 age group, where they were less compliant to home quarantine $(\mathrm{OR}=0.67(0.46-0.97))$, nonetheless more compliant to mask-wearing $(\mathrm{OR}=1.88$ (1.24-2.87)) and hand-sanitising ( $\mathrm{OR}=1.51$ (1.03-2.19)). See online supplemental material 2 for complete regression model output.

\section{DISCUSSION}

To our knowledge, the present study is among the first to examine demographic and social indicators and correlates of the general public's compliance to personal protective measures during the COVID-19 outbreak in China. The main findings from the present study are that 
Table 2 Indicators for compliance with respective mitigation measures

\begin{tabular}{|c|c|}
\hline & $\begin{array}{l}\text { Compliance versus } \\
\text { non-compliance }\end{array}$ \\
\hline & OR $(95 \% \mathrm{Cl})$ \\
\hline \multicolumn{2}{|l|}{ Home quarantine } \\
\hline Gender, male & $0.61(0.51$ to 0.73$)$ \\
\hline Age & $0.99(0.98 \text { to } 0.999)^{*}$ \\
\hline Regional risk-exposure & 0.99 (0.90 to 1.08$)$ \\
\hline $\begin{array}{l}\text { Timeliness for policy } \\
\text { implementation }\end{array}$ & 1.003 (0.99 to 1.02$)$ \\
\hline \multicolumn{2}{|l|}{ Mask-wearing } \\
\hline Gender, male & 1.79 (1.49 to 2.16$)$ \\
\hline Age & $1.03(1.02$ to 1.04$)$ \\
\hline Regional risk-exposure & 1.41 (1.28 to 1.54$)$ \\
\hline $\begin{array}{l}\text { Timeliness for policy } \\
\text { implementation }\end{array}$ & 0.99 (0.98 to 1.01$)$ \\
\hline \multicolumn{2}{|l|}{ Temperature-taking } \\
\hline Gender, male & 1.27 (1.05 to 1.53$)$ \\
\hline Age & 1.005 (0.995 to 1.02$)$ \\
\hline Regional risk-exposure & $1.40(1.28$ to 1.54$)$ \\
\hline $\begin{array}{l}\text { Timeliness for policy } \\
\text { implementation }\end{array}$ & 1.016 (0.998 to 1.035$)$ \\
\hline \multicolumn{2}{|l|}{ Hand-sanitising } \\
\hline Gender, male & 1.14 (0.95 to 1.36$)$ \\
\hline Age & $1.02(1.01$ to 1.04$)$ \\
\hline Regional risk-exposure & $1.39(1.27$ to 1.52$)$ \\
\hline $\begin{array}{l}\text { Timeliness for policy } \\
\text { implementation }\end{array}$ & 1.01 (0.995 to 1.03$)$ \\
\hline
\end{tabular}

Boldface indicates significance, $\mathrm{p}<0.0125$.

${ }^{*}$ Trend to significance $(0.0125<\mathrm{p}<0.05)$.

among all demographic and social factors, age, gender and risk of exposure are the three main indicators for behavioural compliance to the protective measures.

Among all of the mitigation measures various countries have implemented during COVID-19, social distancing has been the most emphasised measure, and proven the most effective one. ${ }^{12}$ China introduced the strict social distancing order in February when the epidemic was spreading at an alarming rate and causing an increasing number of deaths in the nation. ${ }^{5}$ The execution of such an order was combined with home quarantine, the shutdown of all public places, including shops, malls, restaurants and entertainment venues, and forbidding of mass gatherings. With such a rigourous combination, the domestic and global spreading speed of the virus showed a significant slowdown from mid-February till mid-March. ${ }^{13}$

In the present study, men were found less likely to be compliant with the social distancing order $(72 \%$ vs $74 \%)$, nevertheless more likely to follow other personal protective approaches, such as mask-wearing (83\% vs $74 \%)$, temperature-taking $(81 \%$ vs $77 \%)$ and hand-sanitising (77\% vs $75 \%)$. One plausible explanation for the gender difference in the behavioural compliance is that men, especially in the mid-age group, are identified to be the pillar of the family. Hence during a public health emergency like COVID-19, men are more expected to carry on with family errands and even go to work. In the present study, 87 reported violation of the home quarantine order. Among whom, 60 went out for shopping/collection of essential goods (home supplies and grocery), with $67 \%$ of them being men. Apart from this, 24 reported to have left home for work purposes, among whom $67 \%$ were men. Our findings support previous literature that reported men were more likely to leave their homes during the early stages of the COVID-19 outbreak in the Hubei Province and other parts of China. ${ }^{8}$ Interestingly, recent studies investigating behavioural compliance to safety measures (including mask-wearing, isolation) outside of China during COVID-19 have mixed results. ${ }^{14-18}$ Nonetheless, explanation for non-compliance to safety measures centres around the level of knowledge and perception of the COVID-19 pandemic. Similarly, past pandemic research have shown that women are more likely to adhere to more avoidant behaviours such as hand washing and wearing masks. ${ }^{8-1019}$ Conversely, we found that men are more likely to comply with these avoidance behaviours apart from social distancing. Our findings thus demonstrate that the impact of economic conditions alongside the desire to remain safe may be the predominant drivers for the disparities in behavioural compliance. However, behind such a potential driving force lies cultural expectations that adult men are subjected to in Chinese society. From a cultural standpoint, the male breadwinner model still exists in China's social fabric today despite the increasingly blurred gender roles in modern-day China. ${ }^{20}$ The over 2000-year old Confucian model posits a gender role divide between men and women where men undertake an 'outside' role and are expected to provide for the family, while women take on the caregiving role ('inside' role) to tend to household matters. ${ }^{21-24}$ A strong emphasis is also placed on filial piety, where providing and caring for one's elderly parents is an esteemed and obligatory duty. ${ }^{25}$ As a result, the conformity to role expectations in Chinese society may explain the non-compliance by men to social distancing measures as they feel more obligated to meet their economic responsibilities to continue providing for the family, even during a public health crisis. Our results challenge several work on COVID-19 preventive behaviours that view behavioural compliance singularly as the result of partisanship, perceptions surrounding its effectiveness and the infection risks. ${ }^{17} 26$ Our study lends some support to Zhong and colleagues' findings that men were more likely to leave the house to go to crowded places during the outbreak in China, ${ }^{8}$ but contradict in mask-wearing compliance. Higher likelihood of risk-taking behaviour in men was noted as an explanation for their non-compliance. On the contrary, we found that men were compliant to other preventive 


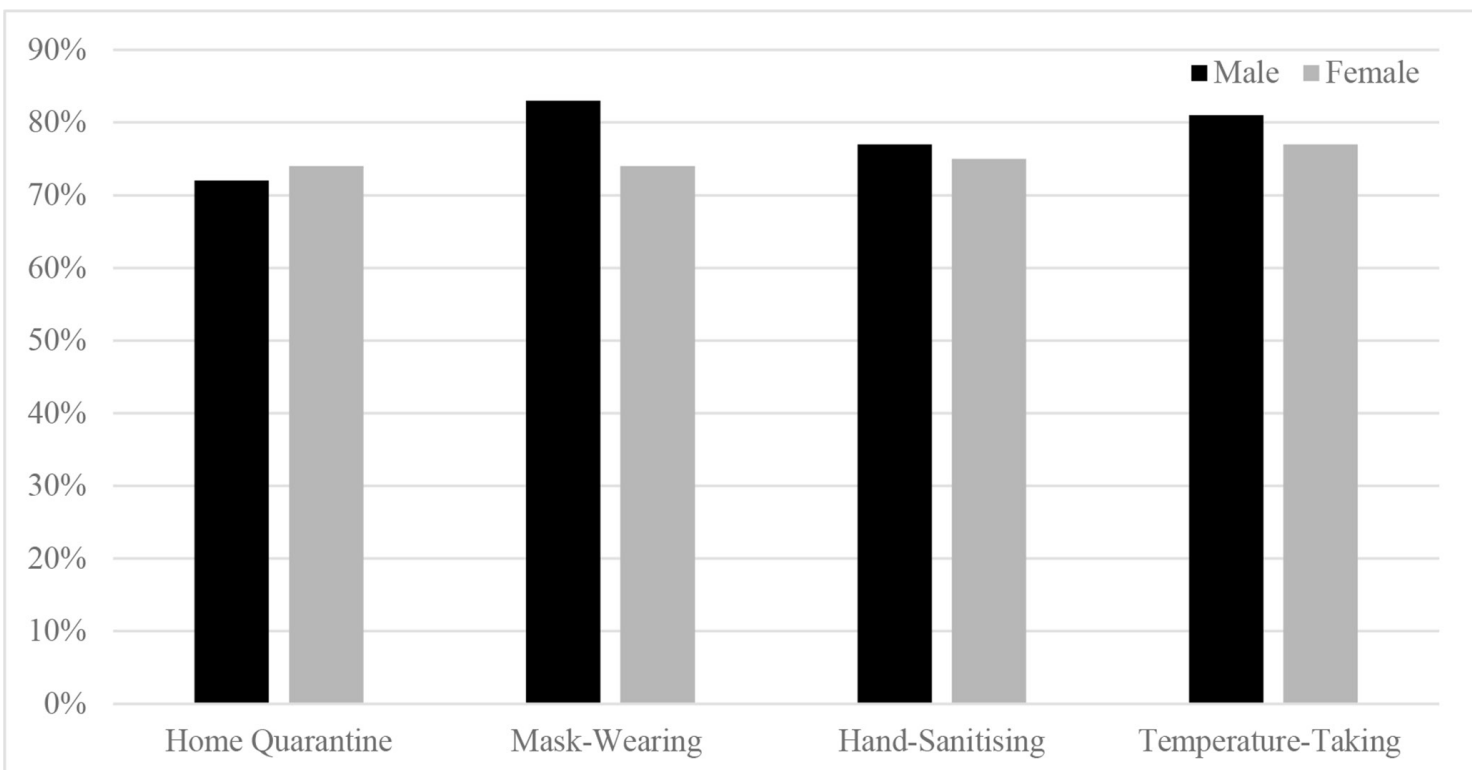

Figure 1 Gender-specific percentages for behavioural compliance.

measures to mitigate risk. Notably, Zhong and colleagues gathered their data between 27 January and 1 February $2020,{ }^{8}$ a week after the lockdown in China, 3 weeks earlier than when our data were collected. Therefore, strict restrictions and public health education by authorities during the 3 weeks may have been effective and enabled men to engage in more preventive measures even though they were still leaving home for work.

Nevertheless, timeliness of policy implementation at provincial level did not have a significant impact on behavioural compliance in the present study. A plausible explanation could be that policy implementation was launched in a prompt manner, according to the outbreak spreading speed in each province. It is worth noting that most provinces announced and implemented the COVID-19 policy within 15 days since the lockdown of Wuhan city. ${ }^{1}$ Such equally speedy reaction at the governmental level may be the reason why there was no difference of policy implementation on personal protective behaviours among community dwellers in China.

Though gender played an important role in predicting compliance with home quarantine in people aged 21 years old and above, it did not make a difference in people under 21 years old. Studies have shown that late adolescents tend not to comply with social distancing and stay home orders due to their likelihood in engaging in risky behaviours. ${ }^{827}$ However, our study found that people in the mid-age group, especially those between 31-40 and 41-50 years old (figure 2) were driving this significance of lower compliance with home quarantine order, as compared with younger adults $<21$ years of age. Notably, those above 50 years old had a higher likelihood of staying home similar to those below 21. A plausible explanation for the reduced social distancing compliance in the 31-50

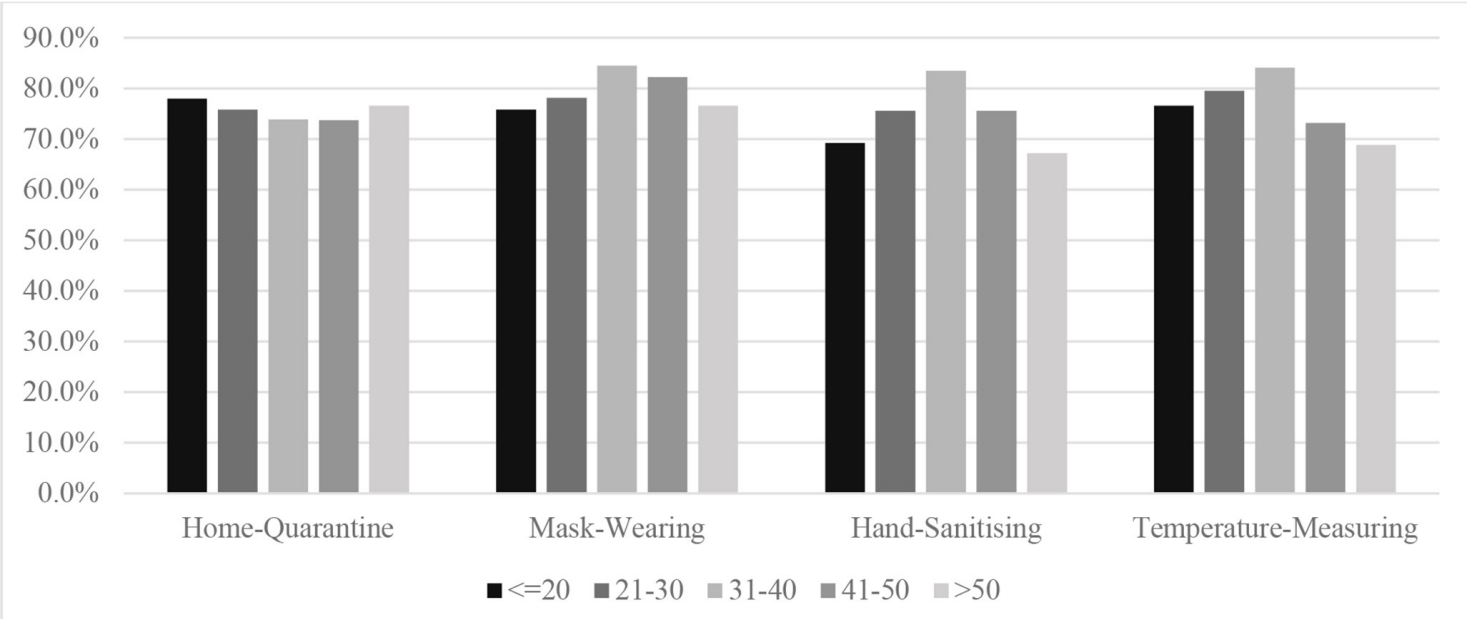

Figure 2 Age-specific percentages for compliance with individual protective behaviours. 


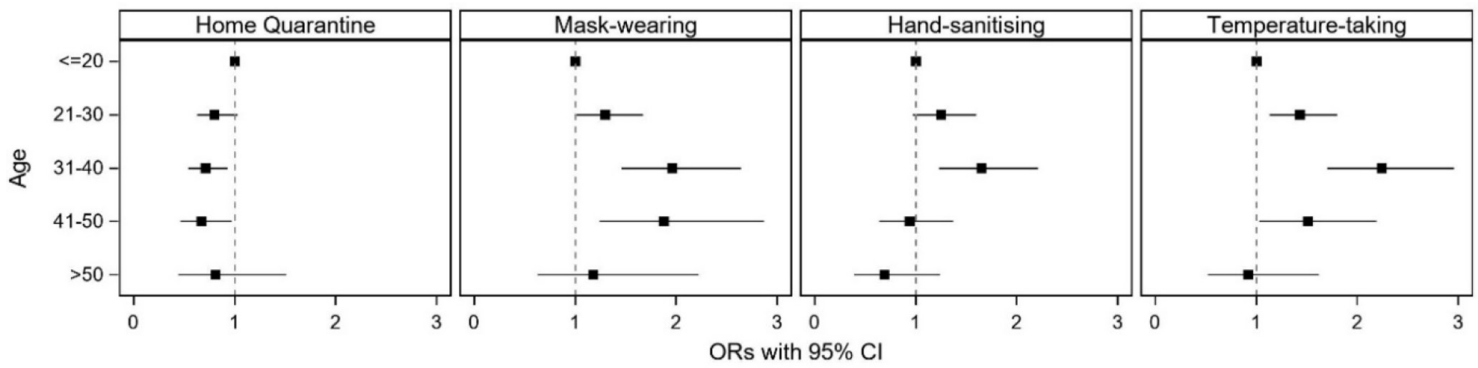

Figure 3 Adjusted ORs and $95 \% \mathrm{Cl}$ of different age-blocks for compliance with individual protective behaviours. Analysis controlled for gender, days to policy implementation and risk exposure.

age group is that a large number of these people may be salarymen and have to leave home for work. On the other hand, those above 50 may be aware of the risks involved and have fewer reasons to leave the house. Furthermore, people in the $>50$ age group may have reduced mobility function. ${ }^{28}$ Hence, those between 31 and 50 years old have lesser compliance to home quarantine due to economic reasons where they have to go out to work compared with those under 21 where majority of them were likely to be high school or university students, hence could not access campus due to temporary shutdown of all schools nationwide during the epidemic. ${ }^{29}$

The present study has several strengths and weaknesses. To our knowledge, the present study is among the first to examine the effect of demographical and social correlates on the compliance of public health mitigation measures, especially social distancing, during the COVID-19 outbreak. Furthermore, the study was conducted during the peak of the spread of COVID-19 in China and gathered nationwide data from participants in China. Therefore, the findings obtained are especially vital in understanding the motivations behind the lack of compliance with mitigation measures, particularly during the heightened period of the outbreak. We observed a difference in adherence to safety measures (eg, mask-wearing) by men between two timeframes of the pandemic in China, ${ }^{8}$ suggesting that public health education and strict restrictions may have impacted the public's perception and compliance. Hence, these results help further inform public health authorities and political leaders in the way they implement mitigation measures and administer financial and psychological aid to the community. Notably, the present study lacked important demographic factors such as education level and occupational status, which could have further informed future mitigation measures. A non-probability sample was used in this study, thus rendering the effect of $p$ values and CIs not strictly valid, or valid only under the assumption that the sample is comparable to a random sample. The study's outcome variables were also self-reported compliance instead of actual compliance, suggesting the potential impact of social desirability bias in under-reporting or over-reporting compliance to safety measures. ${ }^{30}$ However, the online mode of data collection and the anonymity of the survey may have mitigated such potential biases. Moreover, as the study was conducted through an online survey, the sample was limited to those with access to digital technology and Internet. Therefore, we were unable to determine if this subset of the population complied to mitigation measures as well as the factors associated with it. Information obtained from this subset is essential as they may be more vulnerable to the virus due to lack of access to extensive public health awareness and mitigation measures online. While the lack of access to digital technology is a real limitation, future studies should attempt to reach out to this subset of the population. Retrospective studies could be conducted to assess their accordance with mitigation measures, specifically social distancing, and the role of psychosocial indicators and correlates on the compliance. Additionally, it would be interesting to examine the anxiety levels of those in the under 21 group that had a significant impact on their compliance with social distancing during the outbreak. Access to social media and overwhelming information provided by the media every day could be a factor that fuelled the heightened levels of anxiety.

The non-compliance with public health mitigation measures, particularly home quarantine, was largely attributed to the male gender, and being in the middleaged group. Our study found that while men in the midage group were least compliant with social distancing, they were most compliant to other measures (ie, maskwearing, hand-sanitising and temperature-taking), possibly due to their economic responsibilities and need to fulfil the breadwinner role expectation. As the COVID-19 outbreak is still ongoing, public health authorities and governments could target this population in their future measures and aid that are provided during this pandemic.

\section{Author affiliations}

${ }^{1}$ Department of Dig Data and Health Sciences, School of Public Health, Zhejiang University School of Medicine and the Second Affiliated Hospital, Hangzhou, Zhejiang, China

${ }^{2}$ Deparetment of Pharmacology, Yong Loo Lin School of Medicine, National University Singapore, Singapore

${ }^{3}$ School of Public Health, and Department of Endocrinology, Children's Hospital, Zhejiang University School of Medicine, National Clinical Research Center for Child Health, Hangzhou, Zhejiang, China 
Acknowledgements The authors would like to acknowledge all study participants for their cooperation.

Contributors $X X$ and QY conceptualised and designed the study. XX drafted the manuscript. QY supervised data analysis and interpretation of data. XX, ZW and XXH acquired the data. XX and KAC analysed and interpreted the data. XX, ZW and XXH revised the manuscript for intellectual content. QY and KAC critically revised the manuscript for intellectual content.

Funding This study is supported by the National Natural Science Foundation of China (71974170), Soft Science Project of Science Technology Department of Zhejiang Province of China (2019C35025) and Youth Project of the Center for Health Policy and Hospital Management of Zhejiang University (2019WSZ007).

Map disclaimer The funders had no role in study design, data analysis and interpretation, and writing of the manuscript.

Competing interests None declared.

Patient consent for publication Not required.

Ethics approval This study has been approved by the Ethics Commission of Zhejiang University (ID: ZGL202005-01) and was in accordance with the Declaration of Helsinki. Informed consent was obtained from participants prior to taking part in the study.

Provenance and peer review Not commissioned; externally peer reviewed.

Data availability statement Data are available upon reasonable request. All data relevant to the study are included in the article or uploaded as supplementary information. Data are available upon request. Original data can be requested from the study team (xuxinsummer@zju.edu.cn and chianyoung@zju.edu.cn).

Supplemental material This content has been supplied by the author(s). It has not been vetted by BMJ Publishing Group Limited (BMJ) and may not have been peer-reviewed. Any opinions or recommendations discussed are solely those of the author(s) and are not endorsed by BMJ. BMJ disclaims all liability and responsibility arising from any reliance placed on the content. Where the content includes any translated material, BMJ does not warrant the accuracy and reliability of the translations (including but not limited to local regulations, clinical guidelines, terminology, drug names and drug dosages), and is not responsible for any error and/or omissions arising from translation and adaptation or otherwise.

Open access This is an open access article distributed in accordance with the Creative Commons Attribution Non Commercial (CC BY-NC 4.0) license, which permits others to distribute, remix, adapt, build upon this work non-commercially, and license their derivative works on different terms, provided the original work is properly cited, appropriate credit is given, any changes made indicated, and the use is non-commercial. See: http://creativecommons.org/licenses/by-nc/4.0/.

ORCID iD

Kimberly Ann Chew http://orcid.org/0000-0003-3351-4983

\section{REFERENCES}

1 WHO-China Joint Mission. Report of the WHO-China joint mission on coronavirus disease 2019 (COVID-19. World Health organization, 2020.

2 General Office of the People's Government of Hubei Province. Announcement of the People's Government of Hubei Province on Strengthening the Prevention and Control of Pneumonia Caused by New Coronavirus Infection, 2020. Available: http://www.hubei.gov. cn/xxgk/gsgg/202001/t20200122_2013895.shtml

3 World Health Organisation. Coronavirus disease (COVID-19) advice for the public, 2020.

4 Zhang Y, Jiang B, Yuan J. The impact of social distancing and EpiCenter lockdown on the COVID-19 epidemic in mainland China: a data-driven SEIQR model study, 2020.

5 China centre for disease control and prevention. 新型 状病毒肺炎个 人防护怎么做. China, 2020.

6 General Office of the People's Government of Hubei Province. Interim measures for the prevention and control of pneumonia outbreak of novel coronavirus infection in Wuhan, 2020. Available: http://www.hubei.gov.cn/zhuanti/2020/gzxxgzbd/zxtb/202001/ t20200130_2016578.shtml

7 Leung GM, Lam T-H, Ho L-M, et al. The impact of community psychological responses on outbreak control for severe acute respiratory syndrome in Hong Kong. J Epidemiol Community Health 2003;57:857-63.

8 Zhong B-L, Luo W, Li H-M, et al. Knowledge, attitudes, and practices towards COVID-19 among Chinese residents during the rapid rise period of the COVID-19 outbreak: a quick online cross-sectional survey. Int J Biol Sci 2020;16:1745-52.

9 Moran KR, Del Valle SY. A meta-analysis of the association between gender and protective behaviors in response to respiratory epidemics and pandemics. PLoS One 2016;11:e0164541.

10 Bish A, Michie S. Demographic and attitudinal determinants of protective behaviours during a pandemic: a review. $\mathrm{Br} J$ Health Psychol 2010;15:797-824.

11 von Elm E, Altman DG, Egger M, et al. The strengthening the reporting of observational studies in epidemiology (STROBE) statement: guidelines for reporting observational studies. Epidemiology 2007;18:800-4.

12 Kakodkar P, Kaka N, Baig MN. A comprehensive literature review on the clinical presentation, and management of the pandemic coronavirus disease 2019 (COVID-19). Cureus 2020;12:e7560.

13 Hao K. China's travel lockdown sharply slowed the global spread of Covid-19. MIT Technology Review, 2020.

14 Afzal M, Khan A, Qureshi UUR, et al. Community-Based assessment of knowledge, attitude, practices and risk factors regarding COVID-19 among Pakistanis residents during a recent outbreak: a Cross-Sectional survey. J Community Health 2020;13:1-11.

15 Meier K, Glatz T, Guijt MC, et al. Public perspectives on protective measures during the COVID-19 pandemic in the Netherlands, Germany and Italy: a survey study. PLoS One 2020;15:1-17.

16 Mansuri F, Zalat MM, Khan AA, et al. Estimating the public response to mitigation measures and selfperceived behaviours towards the COVID-19 pandemic. Taibah Univ Med Sci 2020;4:1-6.

17 Bruine de Bruin W, Bennett D, de Bruine WB D. Relationships between initial COVID-19 risk perceptions and protective health behaviors: a national survey. Am J Prev Med 2020;59:157-67.

18 Honarvar B, Lankarani KB, Kharmandar A, et al. Knowledge, attitudes, risk perceptions, and practices of adults toward COVID-19: a population and field-based study from Iran. Int $J$ Public Health 2020;65:731-9.

19 de la Vega R, Ruíz-Barquín R, Boros S, et al. Could attitudes toward COVID-19 in Spain render men more vulnerable than women? Glob Public Health 2020;15:1278-91.

20 Attané I. Being a woman in China today: a demography of gender. China Perspectives 2012;2012:5-15.

21 Lebra TS. Confucian gender role and personal fulfillment for Japanese women. Albany, NY: State University of New York Press, 1998: 209-27.

22 Qian Y, Qian Z, Work QZ. Work, family, and gendered Happiness among married people in urban China. Soc Indic Res 2015;121:61-74.

23 Zuo J. From revolutionary Comrades to gendered partners: marital construction of Breadwinning in Post-Mao urban China. J Fam Issues 2003;24:314-37.

24 W-M T. Confucius and Confucianism. In: Confucianism and the family. Vos WHSGAD ed. Albany, New York: State University of New York Press, 1998: 3-36.

25 Stafford C. The roads of Chinese childhood: learning and identification in Angang. Cambridge, UK: Cambridge University Press, 1995.

26 Clements JM. Knowledge and behaviors toward COVID-19 among US residents during the early days of the pandemic: cross-sectional online questionnaire. JMIR Public Health Surveill 2020;6:e19161.

27 Duell N, Steinberg L, Icenogle G, et al. Age patterns in risk taking across the world. J Youth Adolesc 2018;47:1052-72.

28 Gardener EA, Huppert FA, Guralnik JM, et al. Middle-Aged and mobility-limited: prevalence of disability and symptom attributions in a national survey. J Gen Intern Med 2006;21:1091-6.

29 Zhu Q. Why did China close all schools? China Daily, 2020.

30 Nederhof AJ. Methods of coping with social desirability bias: a review. Eur J Soc Psychol 1985;15:263-80. 